\title{
Achieve the Imagination of the Child through a Child-led of Printing Directly on the Fabric Using a Three-Dimensional Printer
}

\author{
Madani, $R$ a, *
}

a Umm Al-Qura University, School of Education, Faculty of Art Education, Makkah, Saudi Arabia

\begin{abstract}
Where children are engaged in design, whether in the classroom or participatory design, the process often involves adults to a greater or lesser extent. Adult involvement has been shown to have a negative influence on children's creative ability in design. This study introduces an independent child-led approach to design by allowing children to print embroidered designs onto textiles using carefully selected technology and materials that do require adult involvement and are suitable for use by children. The approach allows children the opportunity to realise their imaginations without adult impediment and create within a new design paradigm. Using focus groups, the study reveals that children welcome the opportunity to design independently from adults and that such independence leads to motivation and a sense of increased creativity.
\end{abstract}

\begin{tabular}{ll}
\hline Keywords & \\
- & Child-Led \\
- & Independent Design \\
$-\quad$ & Textiles \\
$-\quad$ & 3d Printing \\
\end{tabular}

\section{Introduction}

There is a need to allow children to be independent when they are being creative; this study is based on a new design paradigm that allows the imagination of the child to be realisedwithout the involvement of adults. It has been shown that the involvement of adults in the design process has a negative impact on the child's creativity. Therefore, there's a need to allow children to engage in the creative process without the presence of adults. This study is focused on extending these principles to the design process in the manufacture of embroidered fashion items using $3 \mathrm{D}$ printing. If children are to be independent in this process they need both the design and manufacturing techniques to be suitable for children so that 
they do not require the involvement of adults. This study presents such a technique whereby children print embroidered structures onto fabrics using a 3D printer to create fashion items. The techniques employed are carefully considered so that they can be used by children without requiring the skills or assistance of adults.

One important contribution of this independent design approach is that it allows children to first create the designs on paper and then directly print those designs onto fabric; the advantage is that the children are not restricted by the necessary skills that are required for embroidering material. Moreover, children are also not limited by the choice of materials, as the literature has shown that a choice of materials can have a negative impact on creativity, in this study there's no need for beads, sequins or embroidery materials because the designs can be realised using a 3D printer directly onto fabric.

When children are engaged in textile design in school they are under the influence of the teacher who often engages the child, provides instructions, materials and provides judgment which have been shown to be limitations or impediments to creativity in the design process. The study moves beyond the accepted participatory design paradigm whereby a child is in some way and to some extent engaged in design with an adult.

Moreover, the study is based not only on the principle that children need to create independently but that they also need a real connection with their designs which is achieved through independence and ownership in the design process.

Extending the principles of independent design can only be achieved through careful selection of the techniques used for production which are suitable for independent use by children; this includes consideration of ease of use of technology, materials and safety.

\section{PRELIMINARIES}

\subsection{Adult Involvement and Influence}

According to Gardner (1990) the involvement of adults in a classroom situation influences the style of art that is produced by children. Moreover Gardner (1990) suggests that children on not given the opportunity to create in an alternative way. Meador (1992) agrees with these ideas and says that education can be an inhibitor to the development and creativity of children because they are restricted by social conventions in the classroom. 
Druin (2002) says that children have their own tastes which are different to adults, however, when children design this is often done in consultation with adults which means that children 
become dependent on adults. Durkin (2002) agrees with this idea and says that in design for children the needs of the child are not properly considered.

Although it is commonly accepted that the child is engaged in design with an adult to a certain degree, Read et al. (2002) say is that even if an adult only intends to be a facilitator in participant design it still has a negative impact on the child's ability to be creative, meaning that mere facilitation is not possible if creativity is not to be impeded, adults will always be involved and would always interact and expect outcomes from the child. Pavlou (2006) says that the involvement of the adult no longer allows the child to be spontaneous and the confidence of the child is decreased leading to a low perception of ability, this negatively impacts on the motivation and engagement in creating design.

Burkitt et al. (2010) bring attention to the influence that adults have on children's creativity, specifically, the attitudes and practices of adults have a significant impact on the child's experience of drawing. Given that creativity is something that is considered to be unique and pure, Burkitt et al. (2010) say that teachers that are involved with children in designing place an emphasis on the development of skills and ability with materials rather than creativityitself.

Roth (1996) also says that the teacher can have a negative influence on children when they are engaged in design, he says that such influence can be in the form of making suggestions, providing hints and setting material constraints. Einarsdottir et al. (2009) agrees with these ideas and say that the materials provided and the interaction and support from the teacher has an influence on children's creativity. Even the attitudes of adults towards the designs canhave an effect on children (Rose et al., 2006). Pesanelli (1991) says that children are more creative and imaginative when they are engaged in play and that the presence of an adult can be an impediment in this case.

\subsection{Pure Art}

There is a wide acceptance that design produced by children is pure in its own right. Cizek 1936, Dubuffet (ND), and Viola, 1942 were among the first to advocate the idea of whateveris produced by a child is considered valuable and is a pure representation of their imagination. Additionally, in reference to the above ideas about influence, these ideas suggest that the imagination and ability of a child is often tainted by pedagogical approaches to design. Cizek (1936) believed that there should be no established way of teaching and that there should be absolute minimal involvement from the teacher which would allow the children to foster their imaginations and nurture their creative tendencies because they are allowed to explore freely and have a free choice of materials. 


\subsection{Child-Led Independent Design}

Madani (2016) investigated the idea that when children are engaged with adults in design they have a negative impact on children's creativity. Moreover, in participatory design between adults and children where the product is intended for children does not often reflect what children want. Madani (2016) criticised the current levels of participatory design which include informant design where the child merely informs the adult about what they want, balanced design where the child and the adult are equal participants, and facilitated design where the child creates and the adult merely facilitates (Read et al., 2002). Madani (2016)says that in all cases an adult is always present which has negative effects on creativity. Furthermore, Madani (2016) examines different practical approaches to participatory design and finds that often the adult is involved through offering suggestions, discussion with children and feedback, all of which were found to affect design outcomes.

\subsection{Children and Textile Designs}

Rankin (2006) looks at ways to involve children in the design of textiles, specifically he allows children to experience the aesthetic as well as the functional aspects of textiles through appreciation of furnishings, bedding and curtains, as these have always been deemed to inspire fabric designers. For children he suggests that they design in an environment that they are familiar with, for example designing bedroom furnishings and the design of textiles in a theatre environment whereby children choose the textiles and the fabrics that they want to use for a theatre production, this allows children to see the different types of fabrics that can be used for different types of furnishings.

\subsection{D Printing for Textile Design}

Pei et al. (2015) introduce a technique for printing directly onto fabric using a 3D printer; specifically the technique involves the printing of polymers onto fabrics using the fused deposit modelling (FDM) technique. This technique has applications for the design of fashion items using a 3D printer; it can allow the child to independently print polymer designs directly onto the fabric and is adopted in this study.

Textiles that are produced using additive manufacturing are not currently widely accepted, however, there are a growing number of researchers who are looking into the possibility of printing directly onto fabrics in order to allow flexibility in the fabric [Pei et al., 2015]. Their research involves the investigation of printing logos and designs onto materials and even extends to the manufacture of functional parts such as latches and hooks. There are available 
FDM 3D printing technologies that have been shown to be suitable for use by children

[Madani, 2015] that are applicable in this case.

\section{METHODOLOGY}

The overall aim of the study is to allow children to be creative and design independently of adults. Therefore, it was necessary to develop an approach to design that would allow this. A number of principles were incorporated into both the design and the practical application ofthe design without the involvement of adults. This was to ensure that the design process included the principles of independent design by children. The criteria for the developmentof the design approach were based on the advantages and disadvantages of existing participatory design approaches, where these approaches included involvement and influence such aspects were rejected, and where these approaches included aspects such as freedom, spontaneity and independence, they were adopted. Thus the criteria included that there should be no encouragement, instruction, suggestion and feedback by adults as these were identified forms of adult involvement in participatory design.

The design of this study is comprised of two main parts, firstly the design stage whereby children are given the opportunity to design independently, the second stage is the manufacturing stage, and again children are given the opportunity to manufacture independently. The principles of child-led independent design [Madani, 2016] that have been addressed in the above are applied in all parts of the design and manufacture of textiles and clothing. The initial design process was carried out using the proposed approach by Madani [2016] which involved criteria that allowed to children to design independently of adult involvement and influence.

The development of the employed design approach involved not only the aforementioned principles of independent design established through criteria based on the need for children to design independently free from adults, but also included consideration of safety and ease of use by children. Specifically, the criteria were established through identifying the advantages and disadvantages of existing approaches to participatory design. The approach criteria included that they should be freedom and spontaneity in design, a connection between thechild and the final product, children should be self-reliant, children should be under no pressure to perform, there should be no observation by an adult, there should be no criticism or feedback, no evaluation against marking criteria, no structure to the design process and finally, no restriction of the child's choices in terms of materials.

The methodology also included a focus group that was conducted with the children directly after the design exercise. The focus groups were designed to see how children felt about the 
design process and designing independently. Moreover, the focus groups try to elicit feelings that children have in relation to creativity within the design approach.

\section{The Design Process}

The design process is comprised of two main activities, firstly the initial sketching, andsecondly, the imprinting of designs onto fabric. Both of these processes are developed based on the criteria of the proposed design approach. For the initial design children were given the opportunity in a neutral environment to design freely without any involvement and subsequent influence from adults. The second stage was the imprinting of designs onto the fabric using the $3 \mathrm{D}$ printing a, again here, the principles of independent design are applied whereby children can use the 3D printing technology without supervision from adults.

\subsection{Technique}

Because the design process had to be carried out by children it was necessary to select asuitable technique that would consider both ease of use by children and suitability of materials for use by children. The 3D printer that was chosen was the Ultimaker (2016) afused deposit modelling (FDM) printer commonly used in classrooms today. This printer was found to be suitable because it is already used in educational settings for children, and moreover, the materials that it uses are safe for children. The use of the Ultimaker by school children is well documented and has been used to improve creative skills and is a springboard for more technical 3D printer applications later on in life (Ultimaker, 2016).

It has been established in this study that it important that the children have control over the technology, this is not only important because of the importance of removing the presence and influence of an adult but also because it allows children a greater degree of ownership and independence in the design process, which is one of the main aims of the study. In relation to this requirement, the Ultimaker is simple enough for children to engage directlywith the printer and with little hands-on experience they can easily learn how to use it.

\subsection{Materials}

Specifically, the printer uses both ABS and PLA plastics which are the most popular materials used in 3D printing. ABS is the same material that is used for Lego, however, it is important to note that this material has some disadvantages which may be a disadvantage forthe children because it has a tendency to shrink slightly after cooling and when used on fabrics this may distort the fabric and warping may occur (Pei et al., 2015). Although thereare techniques to overcome these disadvantages, they're too technical for children to facilitate. 
Therefore, it was decided to use PLA because not only does this material not become distorted but it is biodegradable and is more flexible than a ABS which is known to be brittle (Pei et al., 2015). Moreover, PLA has a much nicer finish (Ultimaker, 2016). Pei et al's (2015) study used entry level FDM machines to print PLA and ABS onto fabrics to create designs but also functional parts. Importantly, in line with the principles of the approach to design, these materials are safe for use by children.

\section{RESULTS}

As part of evaluating the independent child-led approach to design a focus group was conducted in order to derive the opinions of the children who participated in the design process. These focus groups allow children to talk about the experience towards understanding whether or not there was a feeling of freedom and independence in the design process. The results of the focus groups clearly showed that children appreciated the benefits of being able to design independently. One of the main themes to emerge from the focus groups was that independence fostered a sense of enthusiasm and motivation to be creative, which in turn was often associated with the idea of being more creative. Further questioning revealed that the children felt that they were ableto foster what was in their imaginations and that design outcomes reflected what they want to produce or what they had in their minds. The focus group discussions also revealed that there was a low level on dependence on adults, where children did miss adult intervention it was in the form of instruction and there was no evidence that theyneeded adults for creativity in design. The children also expressed a real sense of ownership over the process and they were inspired by the future possibilities for their designs.

\section{CONCLUSION}

In conclusion the study set out to allow children the opportunity to be creative and produce embroidered textile design independently from adults. The idea was based on research that showed that the involvement and subsequent influence of adults can have a negative effect on creativity and impede the potential for child to produce pure child-led designs. This was achieved through the careful consideration of the design process where adults were excluded. Moreover, in line with the child-led independent design principle, there was careful selection of technology and materials that could be used by children independently.

The results of the study showed that is possible to reveal a new design paradigm, specifically, pure designs by children not tainted by adult influence. Importantly, it has shown how this 
new paradigm can be achieved which has implications to the development of pedagogy in schools and a rethink of how children and design should be approached.

Importantly, the proposed approach to the design process allowed children more independence when engaged in design, not only has this independence been associated withan increase in creativity but it has also allowed children to take much more ownership of the design process. In reference to the future implications of the findings, they contribute to a better understanding of how children can be more involved in the design process from concept to final product and the realization of a new design paradigm where textiles and fashion for children can be designed by children and not based on adult interpretations or influences.

\section{REFERENCES}

Burkitt, E., Jolley, R. \& Rose, S., 2010. The Attitudes and Practices that Shape Children's Drawing Experience at Home and axt School. International Journal of Art \& Design Education, 29(3), pp.257-270.

Druin, A 2002, 'The role of children in the design of new technology', Behaviour \& Information Technology, 21, 1, pp. 1-25.

Durkin, J. (2002). The need for the development of a child led assessment tool for poweredmobility users. Technology and Disability, 14(4), 163-171.

Einarsdottir, J., Dockett, S. \& Perry, B., 2009. Making meaning: children's perspectives 


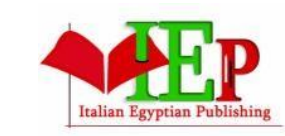

ISSN: 2735-4806

INTERNATIONAL JOURNAL OF

\section{ARTIFICIAL INTELLIGENCE AND EMERGING}

TECHNOLOGY

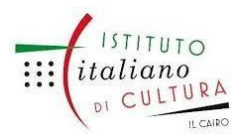

www.egyptfuture.org/ojs/

expressed through drawings. Early Child Development and Care, 179(2),

pp.217-232.Gardner, H. (1990) Art Education and Human Development. Los

Angeles, CA, Getty.

Madani, R (2016) Realising A Child's Imagination Through a Child-Led Product Design forBoth Textile and Three Dimensional Products. Doctorate Thesis. De Monfort University

Pavlou, V 2006, 'Pre-adolescents' Perceptions of Competence, Motivation and Engagement inArt Activities', International Journal Of Art \& Design Education, 25, 2, pp. 194-204.

Pei, E. Shen, J. Watling, J. (2015),"Direct 3D printing of polymers onto textiles: experimentalstudies and applications", Rapid Prototyping Journal, Vol. 21 Iss 5 pp. 556 $-571$

Pesanelli, D 1991, 'Reinventing the children's room', Futurist, 25, 5, p. 28.

Rankin, S. (2006). Textiles Technology Textiles \& Design Activities. Textiles Technology. 1

$-11$.

Read, J. C., Gregory, P., MacFarlane, S., McManus, B., Gray, P., \& Patel, R. (2002, August). An investigation of participatory design with children-informant, balanced and facilitated design. In Interaction design and Children (pp. 53-64). Shaker.

Rose, S, Jolley, R, \& Burkitt, E 2006, 'A Review of Children's, Teachers' and Parents' Influences on Children's Drawing Experience', International Journal Of Art \& Design Education, 25, 3, pp. 341-349.

Ultimaker. (2016). Ultimaker 3D Printing. Available: https://ultimaker.com/. Last accessed20th March, 2016.

Viola, W (1942). Child Art. Bickley: University of London Press Lt

- Ahmed Abdel Azem Mahmoud, Virtual Reality Technology and its Role in Advertising Field, International Journal of Multidisciplinary Studies in Art and Technology, Vol. (1), Issue (1), 2018, 1 - 23.

- Heba Mohamed Okasha Abou ElKamal, Effect of Implementation 5s Methodology in Warehouses at the Egyptian Textiles \& Apparel Factory (Case Study), International Journal of Multidisciplinary Studies in Art and Technology, Vol. (1), Issue (1), 2018, 68 
INTERNATIONAL JOURNAL OF

ARTIFICIAL INTELLIGENCE AND EMERGING

TECHNOLOGY

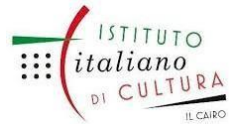

ISSN: 2735-4806

VOLUME 3, ISSUE 2, 2018, 1-20.

www.egyptfuture.org/ojs/

Received: February 15, 2018

Accepted: April 20, 2018 